\title{
Spontaneous course of aortic valve disease
}

\author{
J. Turina, O. Hess, F. SePulCri and H. P. Krayenbuehl \\ Medical Policlinic, Cardiology, University Hospital, Zurich, Switzerland
}

KEY WORDS: aortic stenosis, aortic regurgitation, prognosis.

The fate of patients with aortic valve disease of varying degrees of severity and the relationship between symptoms and haemodynamic status have been studied in 190 adults undergoing cardiac catheterization during the last two decades. During the follow-up period, 41 patients died and 86 underwent aortic valve replacement; these two events were the endpoints for the calculation of 'event-free' cumulative survival. First-year survival in haemodynamically severe disease was $60 \%$ in aortic stenosis and $96 \%$ in aortic regurgitation; in moderate and mild disease (in the absence of coronary artery disease) first-year survival was $100 \%$ in both groups. After 10 years, $9 \%$ of those with haemodynamically severe aortic stenosis and $17 \%$ of those with severe regurgitation were event-free, in contrast to $35 \%$ and $22 \%$, respectively, of those with moderate changes and $85 \%$ and $75 \%$, respectively, of those with mild abnormalities. In the presence of haemodynamically severe disease, $66 \%$ of the patients with stenosis and $14 \%$ of those with regurgitation were severely symptomatic (history of heart failure, syncope or New York Heart Association class III and IV); $23 \%$ of patients with moderate stenosis and $14 \%$ with moderate regurgitation were also severely symptomatic. Only $40 \%$ of those with disease that was severe both haemodynamically and symptomatically with either stenosis or regurgitation survived the first two years; only $12 \%$ in the stenosis group and none in the regurgitation group were event-free at 5 years. Patients with haemodynamically severe aortic stenosis who had few or no symptoms had a 100\% survival at 2 years; the comparable figure for the aortic regurgitation group was $94 \% ; 75 \%$ of the patients in the stenosis group and $65 \%$ in the regurgitation group were event-free at 5 years. In the moderate or mild stenosis and regurgitation groups there was no mortality within the first 2 years in the absence of coronary artery disease, regardless of symptomatic status.

Haemodynamically and symptomatically severe aortic stenosis and regurgitation have a very poor prognosis and require immediate valve surgery. Asymptomatic and mildly symptomatic patients with haemodynamically severe aortic stenosis are at low risk and surgical treatment can be postponed until marked symptoms appear without a significant risk of sudden death. In severe aortic regurgitation, the decision for surgery should depend not only on symptoms but should be considered in patients with few or no symptoms because of risk of sudden death. In the absence of coronary artery disease, moderate aortic valve disease does not require valve operation for prognostic reasons.

Timing of valve replacement in chronic aortic valve disease is based on the knowledge of the spontaneous course of the disease and the risk and outcome of the operation. Whereas there is an abundant literature on surgical results, studies on the spontaneous course of the disease are rare, especially in patients who have undergone heart catheterization $^{[1-11]}$. Most reports on the spontaneous course are based solely on symptoms and non-invasive clinical evaluation and stem from

Submitted for publication on 3 September 1986 and in revised form 4 November 1986.

Adtress for carrespandence: Dr J. Turina, Medical Pobiclinic, University Hospital, 809I Zurich, Switzerland. the period before heart catheterization became routine ${ }^{[12-23]}$. Thus, the exact haemodynamic situation of patients included in these studies was not known. Marked changes in patient population during recent decades, such as the rapid decline in incidence of rheumatic heart disease, increasing age of the patients and increase in frequency of coronary artery disease, make these reports even less representative for the current situation. In the present study we demonstrate the long-term course of patients with aortic valve disease of various severity who have been evaluated by heart catheterization. The emphasis is on the prognostic value of haemodynamic and clinical variables and their relationship. 
Table I Distribution of aortic valve disease patients according to haemodynamic severity

\begin{tabular}{lcccc}
\hline & No. of & \multicolumn{3}{c}{ Seventy of the disease } \\
\cline { 3 - 5 } & patients & severe & moderate & mild \\
\hline Stenosis & 73 & 39 & 30 & 4 \\
Regurgitation & 80 & 36 & 36 & 8 \\
Combined lesion & 37 & 11 & 14 & 12 \\
\hline
\end{tabular}

\section{Material and methods}

This study is based on clinical, haemodynamic and angiographic data of 190 patients with aortic valve disease, 152 men and 38 women, who underwent heart catheterization between 1963 and 1983 . At the time of catheterization the age ranged between 16 and 75 years (mean 43 years). This patient population was studied retrospectively by searching the records of our clinic between 1970 and 1983 for patients in whom heart catheterization was performed but who were not admitted to surgery. Operation was not carried out because either aortic valve disease was of minor degree, or the patients declined operative treatment or they died before a recommended operation. We have also included patients being operated during the 1970-1983 period but undergoing first heart catheterization years before. We have excluded patients who had primary myocardial disease with only mild additional aortic valve disease, patients with additional haemodynamically significant mitral valve disease and patients dying a non-cardiac death. These 190 patients represent $86 \%$ of all available patients of our clinic.

All patients underwent right and left heart catheterization and all but 7 underwent angiography. In all but 14 patients aortic regurgitation was quantified by thermodilution. Cardiac index was determined by Fick and/or thermodilution methods and when both methods were available the average of the 2 values was tabulated. Aortic valve orifice area was calculated by the Gorlin formula ${ }^{[24]}$. Quantitative analysis of left ventricular angiograms was performed regularly after 1973 and thus these data were available only in a part of patients. Coronary arteriography was regularly performed after 1970 in patients with angina pectoris as well as patients over 45 years of age.

All patients were classified according to their clinical and haemodynamic findings at the time of the first heart catheterization. The criterion for haemodynamic severity of the disease was valve orifice area for aortic stenosis $\left(<0.9 \mathrm{~cm}^{2}\right.$ severe, $0.95-1.4 \mathrm{~cm}^{2}$ moderate, $>1.5 \mathrm{~cm}^{2}$ mild) and the magnitude of regurgitant fraction for aortic regurgitation ( $>45 \%$ severe, $25 \%-44 \%$ moderate, $<25 \%$ mild). In 15 patients, all but one having moderate or mild disease, whose valve orifice area was not calculated mean pressure gradient was used as a criterion for severity. A pressure over $50 \mathrm{mmHg}$ indicated severe and below $20 \mathrm{mmHg}$ mild disease. In 14 patients without thermodilution, angiographic criteria for severity of aortic regurgitation were applied. Patients having both stenotic and regurgitant lesions of similar degree were classified as combined aortic valve disease. Patients having severe aortic stenosis or regurgitation accompanied by only mild or minimal regurgitant or stenotic lesions were not classified as combined aortic valve disease. Classification of patients in different groups according to the haemodynamic severity of the disease is presented in Table 1.

\section{FOLLOW-UP}

The great majority of the patients was followed in our clinic and 82 patients underwent a second catheterization. Information about patients dying out of hospital or being followed elsewhere were obtained by contacting the patients' physicians and families. Patients were followed for up to 20 years after initial heart catheterization, mean follow-up being 6.6 years. During the follow-up 43 patients died and 86 underwent aortic valve surgery. Patients undergoing valve surgery were followed further for an average of 4 years.

\section{STATISTICAL EVALUATIONS}

Survival of the patients was calculated according to the life table method ${ }^{[25]}$ beginning with the initial 
heart catheterization. The endpoints for calculation of event-free survival were death and aortic valve surgery; for calculation of the effective, true survival the endpoint was only death regardless whether aortic valve surgery was performed or not. Additional statistical analysis was performed with the paired Student $t$-test and chi-square test as appropriate. For comparison of the actuarial survival curves the method of Peto and Pike was applied ${ }^{[26]}$.

\section{Results}

SURVIVAL

During the follow-up 43 patients died, all of them of cardiac or probable cardiac death; 19 patients died before recommended valve surgery could be performed (all within 7 months after heart catheterization), 15 refused operative treatment, in 5 cases surgical treatment had not been recommended and 4 died while out of our control. Aortic valve surgery was performed in 86 patients and all but one patient with commissurotomy underwent valve replacement. Among additional surgical procedures were aorto-coronary bypass in 4 patients, various interventions on the ascending aorta in 13 and mitral valve surgery in 5 patients because haemodynamically significant mitral regurgitation developed during the follow-up. Perioperative mortality was $3.5 \%$ ( 3 patients) and during the later follow-up 8 patients died. Modern procedures of intraoperative myocardial protection (hypothermic cardioplegia) have been applied from 1975 onwards. Event-free and effective survival in patients with aortic stenosis and regurgitation is presented in Fig. 1. The proportion of patients with haemodynamically severe and moderate disease was similar in both groups (Table 1). During the first year mortality rate was $22 \%$ in aortic stenosis and $4 \%$ in aortic regurgitation; at 10 years $20 \%$ of patients with stenosis and $23 \%$ of patients with regurgitation were event-free (no death, no operation). In the aortic stenosis group none of the patients underwent valve surgery during the first 2 years of follow-up, in aortic regurgitation 3 patients were operated upon during the second year; effective survival after 10 years was $57 \%$ in aortic stenosis and $76 \%$ in aortic regurgitation. This difference in effective survival after 10 years is not a consequence of different survival of operated patients with aortic stenosis and regurgitation but reflects the different first-year survival in the two groups. Patients with combined aortic valve disease

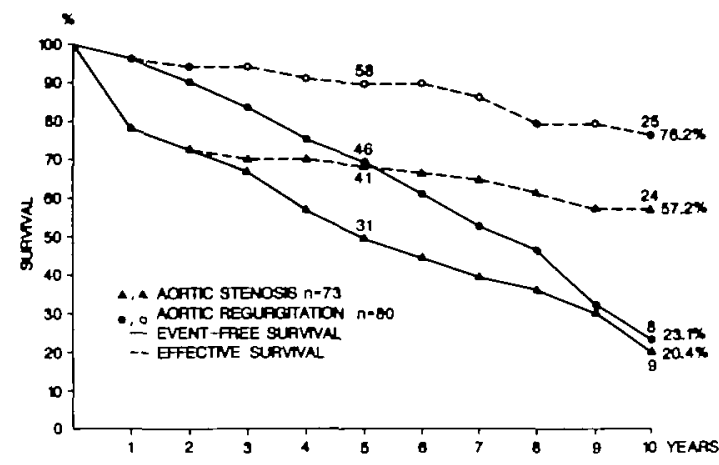

Figure 1 Event-free and effective cumulative survival of 73 patients with aortic stenosis and 80 patients with aortic regurgitation since the first heart catheterization. Number of patients with complete 5 and 10 year follow-up is indicated in each group

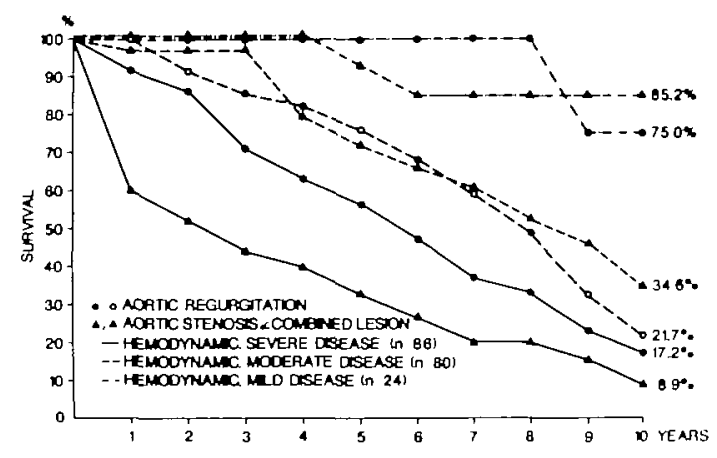

Figure 2 Event-free survival in aortic stenosis and combined aortic lesion as well as in aortic regurgitation in relation to the initial haemodynamic severity of the aortic valve disease.

had a first year mortality of $13.5 \%$; none of the patients was operated upon within the first 2 years; 10 year event-free survival was $46 \%$ and effective survival $79 \%$. This, at first glance, particularly favourable survival is, however, due to a high proportion of patients with haemodynamically mild disease in this group (Table 1).

Figure 2 demonstrates event-free survival of the patients in relation to the haemodynamic severity of the disease. Survival curves of patients with combined lesion and those with aortic stenosis were very similar and these 2 groups are, therefore, presented together. In the presence of haemodynamically severe disease first year survival was $60 \%$ in aortic stenosis and combined lesion group, and $92 \%$ in aortic regurgitation group; at 10 years $9 \%$ of patients with stenosis or combined lesion and $17 \%$ of patients with regurgitation were event-free. 
Table 2 Event-free survival it patients with aortic stenosis and regurgitation in relation to unitial symptoms and findugs $\left({ }^{* * *} P<0.001{ }^{* *} P<0.01, * P<005\right)$

\begin{tabular}{|c|c|c|c|c|c|c|}
\hline & \multicolumn{6}{|c|}{ Event-free survival } \\
\hline & \multicolumn{3}{|c|}{ Aortic stenosis and combined lesion } & \multicolumn{3}{|c|}{ Aortic regurgitation } \\
\hline & 5 yea & & 10 year & 5 year & & 10 year \\
\hline $\begin{array}{l}\text { NYHA class III and IV } \\
\text { NYHA class I and II }\end{array}$ & $\begin{array}{l}22 \% \\
76 \%\end{array}$ & *** & $\begin{array}{r}4 \% \\
43 \%\end{array}$ & $\begin{array}{l}29 \% \\
73 \%\end{array}$ & $*$ & $-27 \%$ \\
\hline $\begin{array}{l}\text { With heart failure } \\
\text { Without heart failure }\end{array}$ & $\begin{array}{c}0 \% \\
68 \cdot 5 \%\end{array}$ & $* * *$ & - & - & & - \\
\hline $\begin{array}{l}\text { Syncope } \\
\text { Without syncope }\end{array}$ & $\begin{array}{l}30 \% \\
65 \%\end{array}$ & $* *$ & $\begin{array}{c}0 \\
36 \%\end{array}$ & - & & - \\
\hline $\begin{array}{l}\text { Angina pectoris } \\
\text { No angina pectons }\end{array}$ & $\begin{array}{l}39 \% \\
68 \cdot 5 \%\end{array}$ & $* *$ & $\begin{array}{l}14 \% * * \\
39 \%\end{array}$ & $\begin{array}{l}52 \cdot 5 \% \\
76 \%\end{array}$ & $*$ & $\begin{array}{l}20 \% \\
26 \%\end{array}$ \\
\hline $\begin{array}{l}\text { End-diastolic pressure } \geqslant 15 \mathrm{mmHg}^{-} \\
\text {and/or cardiac index }<2.51 \mathrm{~min}^{-1} \mathrm{~m}^{-2} \\
\text { end-diastolic pressure }<15 \mathrm{mmHg}^{-1} \\
\text { and/or cardiac index } \geqslant 2.51 \mathrm{~min}^{-1} \mathrm{~m}^{-2}\end{array}$ & $\begin{array}{l}38 \% \\
77 \%\end{array}$ & $* * *$ & $\begin{array}{l}24 \% \\
34 \%\end{array}$ & $\begin{array}{l}54 \% \\
79.5 \%\end{array}$ & * & $\begin{array}{l}15 \% \\
32 \%\end{array}$ \\
\hline
\end{tabular}

Within the first two years, no operation was performed in either group, event-free and effective survival being thus identical for this period; at 10 years effective survival was $35 \%$ in aortic stenosis and combined lesion group and $68.5 \%$ in aortic regurgitation group. In the haemodynamically moderate aortic stenosis and combined lesion group, one patient with additional coronary artery disease died within the first year (first-year survival rate of $97 \%$ ), at 10 years $35 \%$ of the patients were still event-free. None of these patients has been operated during the first 3 years; 10 year survival was $85 \cdot 5 \%$. In moderate aortic regurgitation none of the patients died during the first 4 years but 3 patients were operated during the second year; at 10 years $22 \%$ of the patients were event-free, effective survival at that time was $79 \%$. In haemodynamically mild aortic valve disease only one patient previously successfully operated for coarctation underwent aortic valve replacement within the first 5 years. None of the patients died during the follow-up in this group; after 10 years $85 \%$ of patients in the aortic stenosis and combined lesion group and $75 \%$ of patients with aortic regurgitation were event-free.

Table 2 demonstrates event-free survival of the patients with aortic valve disease in relation to initial symptoms and findings. Patients with isolated aortic stenosis and those with combined lesions are grouped together due to similar symptomatic status. In aortic stenosis and combined lesions, the presence or history of heart failure, syncope, angina pectoris and serious functional limitation according to New York Heart Association classes III and IV were connected with reduced 5 and 10 year event-free survival. The highest predictive value was possessed by a history of heart failure followed by syncope and serious functional limitation. In aortic regurgitation, patients in New York Heart Association classes III and IV or with angina pectoris had a significantly reduced 5 year event-free survival. In aortic regurgitation, the number of patients with the symptoms of heart failure or syncope was small, hence related survival was not assessed. Signs of depressed left ventricular function such as end-diastolic pressure $\geqslant 15 \mathrm{mmHg}$ and/or cardiac index below $2.51 \mathrm{~min}^{-1} \mathrm{~m}^{-2}$ were also related to reduced 5 and 10 years survival in both groups of patients with aortic valve disease.

RELATION BETWEEN SYMPTOMS AND HAEMODYNAMIC SEVERITY

The frequency of various symptoms in severe, moderate and mild aortic valve disease is represented in Fig. 3. Patients with aortic stenosis and combined lesions are again grouped together due to very similar symptomatic status. In haemodynami- 


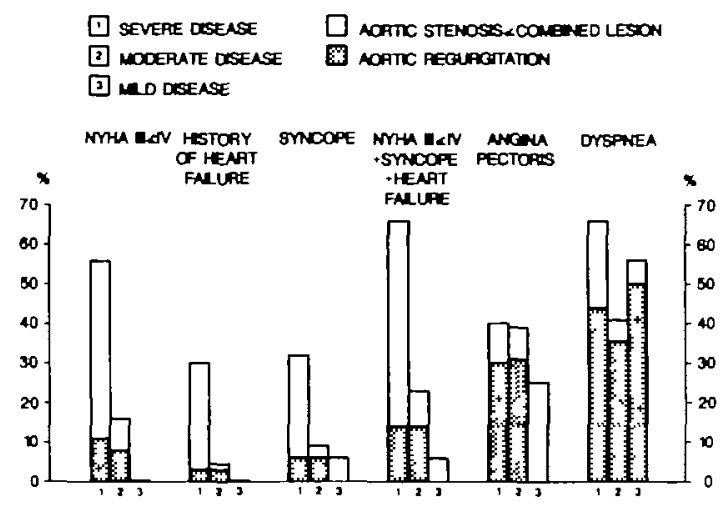

Figure 3 Relative frequency of different symptoms in haemodynamically severe, moderate and mild aortic stenosis and regurgitation (NYHA $=$ New York Heart Association class).

cally severe aortic stenosis and combined lesions, $56 \%$ of patients were in New York Heart Association classes III and IV; $30 \%$ had a history of heart failure and $32 \%$ had had a syncopal attack. At least one of these symptoms was present in $66 \%$ of the patients with severe disease. These symptoms were also found in patients with moderate aortic stenosis. Thus, $16 \%$ of patients with moderate disease were in New York Heart Association classes III and IV, $5 \%$ had a history of heart failure, and $9 \%$ had had syncope; at least one of these features was present in $23 \%$ of patients. Three of the seven patients in New York Heart Association classes III and IV, both patients with a history of heart failure, and one of the four patients with syncope had additional coronary artery disease. In mild aortic stenosis none of the patients was severely functionally limited, there were no heart failure symptoms but one patient had had a syncopal attack due to complete atrio-ventricular block. Angina pectoris was present in $40 \%$ of the aortic stenosis patients with haemodynamically severe, in $39 \%$ of patients with moderate and $25 \%$ of patients with mild aortic stenosis and combined lesion. Dyspnoea was present in $66 \%$ of patients with severe, $41 \%$ with moderate and $57 \%$ with mild aortic stenosis and combined lesions.

In aortic regurgitation, only $12 \%$ of patients with haemodynamically severe disease were in New York Heart Association classes III and IV, only one $(3 \%)$ had a history of heart failure and only 2 had had a syncope. One or another of these features was present in $14 \%$ of the entire group of patients with severe regurgitation. The same proportion of patients with these symptoms was found in moderate aortic regurgitation. Angina pectoris was present in a similar proportion of patients with severe $(30 \%)$ and moderate $(31 \%)$ aortic regurgitation. Dyspnoea was present in $44 \%$ of patients with severe, in $36 \%$ of patients with moderate and $50 \%$ of patients with mild aortic regurgitation.

Severely symptomatic patients (patients in New York Heart Association classes III and IV as well as patients with heart failure and syncope) with severe aortic stenosis had a higher mean aortic pressure gradient ( 69 vs $57 \mathrm{mmHg}$, NS), smaller aortic valve orifice area $\left(0.56\right.$ vs $\left.0.76 \mathrm{~cm}^{2}, P<0.01\right)$ lower cardiac index $\left(2.6\right.$ vs $\left.3.31 \mathrm{~min}^{-1} \mathrm{~m}^{-2}, P<0.01\right)$ and higher left ventricular end-diastolic pressure (17 vs $12 \mathrm{mmHg}, P<0.05$ ) than asymptomatic and mildly symptomatic patients of the same group (Fig. 4). These group differences have little importance for decision-making in individual patients because a very wide overlap between the groups existed. In haemodynamically severe aortic regurgitation regurgitant fraction exceeded $50 \%$ in all 5 severely symptomatic and in only 15/30 asymptomatic and midly symptomatic patients; cardiac index was below $2.51 \mathrm{~min}^{-1} \mathrm{~m}^{-2}$ in $2 / 5$ severely symptomatic and $3 / 30$ asymptomatic or midly symptomatic patients; left ventricular end-diastolic pressure exceeded $14 \mathrm{mmHg}$ in $4 / 5$ severely symptomatic and $14 / 31$ mildly symptomatic patients. Quantitative evaluation of left ventricular angiography was performed in only a proportion of patients. All 7 asymptomatic or mildly symptomatic patients with severe aortic stenosis or combined lesion had a normal ejection fraction ( $>55 \%$ ) whereas severely symptomatic patients had a wide range of ejection fractions from $18 \%$ to $72 \%$ and only $9 / 21(43 \%)$ had a normal value. In severe aortic regurgitation 10/11 asymptomatic and mildly symptomatic patients had a normal ejection fraction whereas in all 4 severely symptomatic patients ejection fraction was decreased.

THE PROGNOSTIC VALUE OF SYMPTOMS AND HAEMODYNAMICS FOR SURVIVAL

In the presence of haemodynamically severe aortic valve disease, survival of severely symptomatic patients (patients in New York Heart Association classes III and IV as well as patients with heart failure and syncope) was very different from that of asymptomatic or mildly symptomatic patients (patients in New York Heart Association classes I and II) (Figs 5 and 6). In a group of 33 patients with haemodynamically and symptomatically severe 


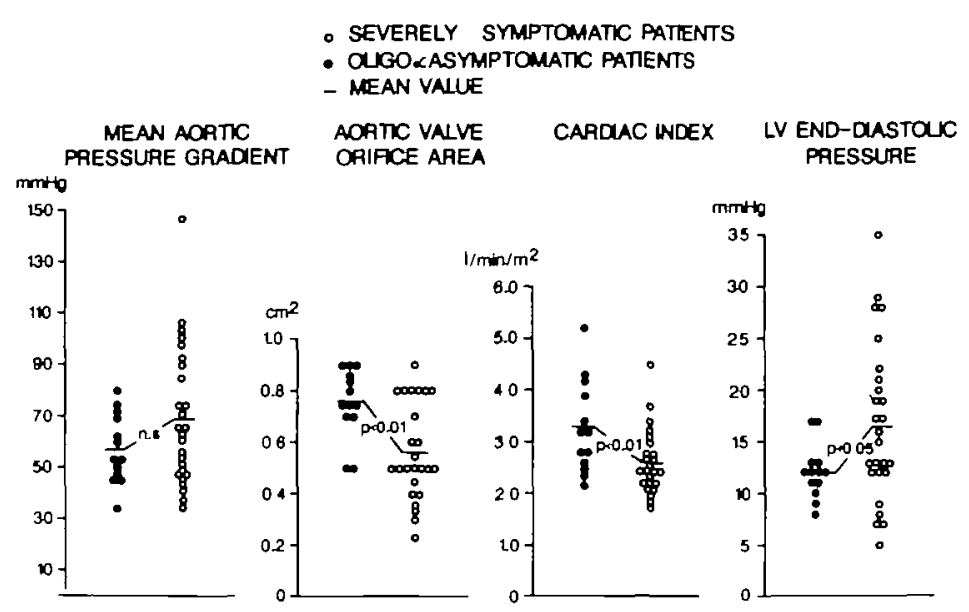

Figure 4 Haemodynamically severe aortic stenosis: mean aortic pressure gradient, valve orifice area, cardiac index and left ventricular end-diastolic pressure in severely symptomatic and asymptomatic or mildly symptomatic patients. Mean value and statistical difference between both groups are indicated (NS= not significant).

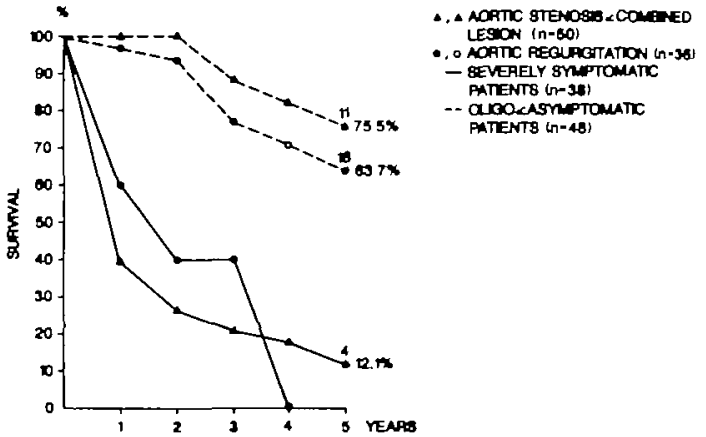

Figure 5 Event-free survival in haemodynamically severe aortic stenosis and combined lesion as well as aortic regurgitation in severely symptomatic and asymptomatic or muldly symptomatic patients.

aortic stenosis or combined lesions, only $27 \%$ survived 2 years and only $12 \%$ were event-free at 5 years; effective survival at 5 years was $22 \%$. In a small group of 5 patients with haemodynamically and symptomatically severe aortic regurgitation, none survived 4 years. In a group of 17 asymptomatic or mildly symptomatic patients with severe aortic stenosis or combined lesions, none of the patients died or was operated during the first 2 years; at 5 years $75 \%$ of them were event-free and $94 \%$ survived. In a group of 31 asymptomatic or midly symptomatic patients with severe aortic regurgitation, 2 sudden and otherwise unexpected

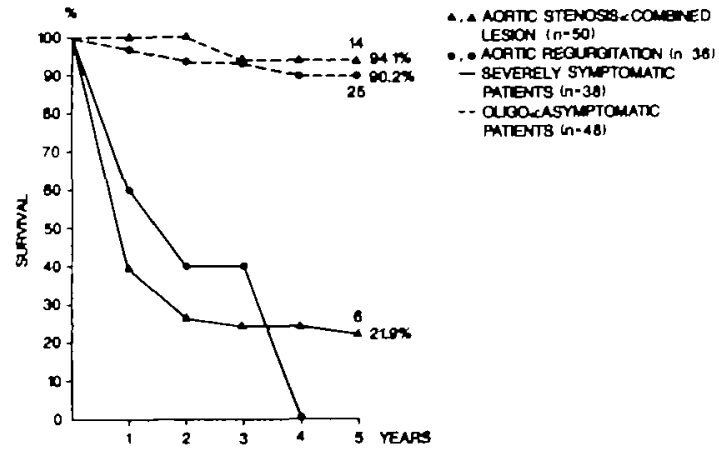

Figure 6 Effective survival in haemodynamically severe aortic stenosis and combined lesion as well as aortic regurgitation in severely symptomatic and asymptomatic or mildly symptomatic patients.

deaths occurred within the first 2 years ( 2 year survival of $94 \%$ ) and at 5 years effective survival was $90 \%$ and was event-free in $64 \%$.

In the group with moderate aortic disease, 15 patients, 10 with aortic stenosis or combined lesions and 5 with aortic regurgitation, were severely symptomatic. Only one patient with additional coronary artery disease died within the first follow-up year. There was no death in this group within the first 4 years. In the asymptomatic and mildly symptomatic group, none of the patients died but $27 \%$ underwent valve surgery within 5 years. 


\section{MODE OF PROGRESSION}

During the follow-up 82 patients underwent a second catheterization. The New York Heart Association class and the most relevant haemodynamic data at the first and second catheterization are presented in Table 3 . The second catheterization was usually performed because of symptomatic or haemodynamic deterioration. Thus, at the second catheterization all but 8 patients were in a higher New York Heart Association class and in all 3 patient groups there was a significant increase in mean New York Heart Association class. In a group of 64 patients followed noninvasively there was no significant change in New York Heart Association class from the initial to the last examination. Between the first and second heart catheterizations there was a significant increase in mean pressure gradient and decrease in valve orifice area in the aortic stenosis and combined lesions group as well as significant increase of the regurgitant fraction in aortic regurgitation. In all 3 groups, left ventricular end-diastolic pressure increased significantly whereas the decrease in cardiac index, present in all 3 groups, did not reach the level of statistical significance. In the aortic stenosis group at second catheterization 2 patients showed a haemodynamically significant aortic regurgitation but none developed significant mitral regurgitation. In the aortic regurgitation group, no haemodynamically significant stenotic lesion became manifest but 4 patients developed an aneurysm of the ascending aorta and another 4 mitral regurgitation. In the patients with a combined lesion, the severity of stenosis increased in all 16 patients, the regurgitant fraction increased in 11 and decreased in 4 patients. The rate of progression of the aortic valve disease was not predictable in individual cases because even within 2 to 3 years, severe aortic stenosis or regurgitation occurred in previously moderate disease whereas even after 10 years some patients with severe disease showed no progression. In aortic stenosis, patients with haemodynamically severe disease usually had the second catheterization earlier than those with moderate disease ( 77 months vs 89 months) but there was a wide overlap between the two groups.

\section{CORONARY ARTERY DISEASE}

Seventeen patients had or developed coronary artery disease (stenosis over $50 \%$ ) during the followup period. Isolated aortic stenosis was present in 12 patients ( $16 \%$ of all patients with aortic stenosis), combined lesions in 3 (8\% of entire group with combined lesion) and in 2 aortic regurgitation (2.5\% of the entire group). Despite moderate or severe aortic valve disease $4 / 17(24 \%)$ patients were free of angina pectoris. In aortic stenosis, the only group with a relevant number of patients with coronary artery disease, $50 \%$ of patients with additional coronary artery disease died within the first follow-up year and only $20.5 \%$ were event-free at 5 years. In aortic stenosis without coronary artery disease only $16 \%$ died during the first year and $60 \%$ were eventfree at 5 years.

\section{VALVE ENDOCARDITIS}

During the follow-up, 6 patients had acute endocarditis, the overall incidence of endocarditis being $0.53 \%$ per patient-year. One patient died during the acute phase of endocarditis, 5 were successfully treated but rapid deterioration of the haemodynamic and symptomatic status ensued and within one year after endocarditis, all 5 patients underwent valve replacement. In addition to aortic valve replacement, mitral valve surgery was carried out in two cases.

\section{Discussion}

Today, studies on the true, natural course of aortic valve disease cannot be performed because patients developing severe, symptomatic disease are admitted for surgery. Thus reports have concerned either patients who declined surgery or died before operation $^{[10,11,28,29]}$ or the survival of patients with less advanced disease followed until operation [3.5-8,30.31]. Even here some reservation about studies based solely on symptomatic status and clinical signs is in order because haemodynamic severity and possible additional heart disease such as coronary artery disease may be inaccurately assessed ${ }^{[15]}$. The purpose of our study was to assess the fate of patients with aortic valve disease of various degrees of severity during the last two decades and to evaluate the relation between symptoms and haemodynamic status. Hence, only patients undergoing heart catheterization were included and their outcome was evaluated from the time of initial invasive examination until death or cardiac surgery. Thus, haemodynamic and clinical status at the beginning of the study were clearly defined and because follow-up data were available in $86 \%$ of the patients, the presented data can be regarded as representative of experience in our clinic.

Some drawbacks of such a study should not be overlooked. Aortic valve disease is not very frequent and heart catheterization as an invasive and 


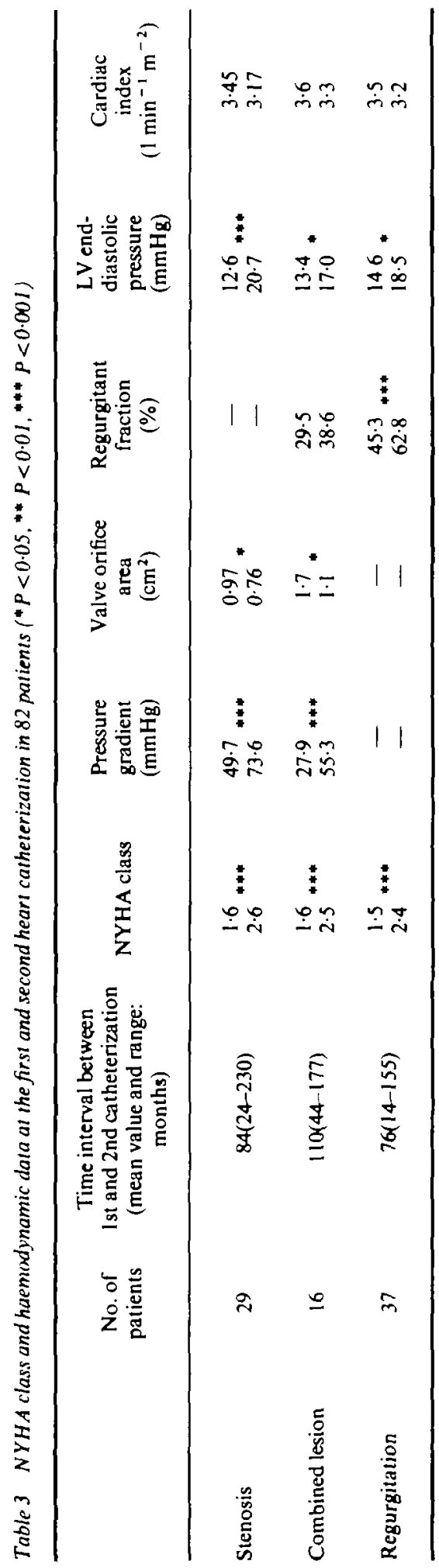


potentially dangerous procedure is performed usually only in patients who are candidates for surgical treatment or where discrepancies between the history, symptoms and objective clinical findings require assessment of true haemodynamic situation. Thus, a relative long period of time elapsed until a sufficient number of patients was obtained; medical and surgical treatment has changed considerably during this period. The number of symptomatic patients in mild and probably also in moderate aortic valve disease group is too high and not representative for the whole population of these patients due to our sampling modus. Patients dying before recommended operation represent some sort of a 'spontaneous' negative selection and their inclusion in the study tends to magnify the true death risk in the absence of surgery.

In this study, the outcome of the patients is presented by actuarial methods in two different ways. Patient survival in the absence of death and operation was labeled 'event-free'. Here death and operation were regarded as identical events. A similar type of data presentation has been also applied in other studies ${ }^{[22,23]}$. Additionally, the true outcome of the patients was also presented and called effective survival. Here, patients were not withdrawn from the follow-up at the time of cardiac surgery but their outcome after operation was further pursued. Patients undergoing aortic valve replacement are not restored to normal health but remained exposed, apart from the currently very small operative risk, to the morbidity and mortality risk directly related to artificial valves such as thromboembolism, endocarditis and mechanical failure of the prosthesis.

Aortic stenosis as compared to aortic regurgitation is generally regarded as a more serious disease with a rapid progression and bad survival once symptoms occur ${ }^{[32-34]}$. In some aspects our data are at variance with this opinion. For a given haemodynamic severity, a much higher proportion of patients in the stenosis than in the regurgitation group is severely symptomatic and functionally disabled but survival of patients with haemodynamically and symptomatically severe disease is in both groups similar. Asymptomatic and mildly symptomatic patients with severe disease as well as patients with moderate and mild disease had also a similar long-term event-free survival. Thus, in our experience the proportions of patients surviving 10 years do not differ significantly. These data demonstrate that any comparison between stenotic and regurgitant aortic valve lesion is only valid if patients with similar haemodynamic and symptomatic status are concerned. Outcome of the patients with combined stenotic and regurgitant lesions is quite similar to that of isolated stenosis; thus these two patients group were evaluated together.

In addition to haemodynamic severity of the disease, the degree of functional disability and symptomatic status emerged as predictive variables for survival in aortic valve disease. The presence or history of heart failure, syncope and severe functional limitation according to New York Heart Association classes III and IV should be regarded in aortic stenosis as well as in aortic regurgitation as harbingers of poor outcome. Our data resemble closely previously reported ones (Tables 4-6). These symptoms, usually associated with haemodynamically severe disease, can also be present in certain patients with only moderate or even mild disease $\mathrm{s}^{[2,15,35,36]}$. In the majority, additional coronary artery disease is the cause for this discrepancy but one should not forget that under certain circumstances such as vigorous sporting activity or complete atrioventricular block, syncopal attacks can occur even in aortic stenosis of minor degree. Psychical embarrassment and fear, especially in patients confronted recently with their own cardiac disease and also the tendency for aggravation in patients who desire a secondary gain can easily lead to exaggeration of complaints. The assessment of true functional capacity by bicycle ergometry is indispensable in such cases. In the absence of coronary artery disease, there is no need for immediate surgery regardless of symptomatic status.

Even in the presence of haemodynamically severe, disease, one third of the aortic stenosis and $85 \%$ of the aortic regurgitation patients were asymptomatic or mildly symptomatic. It is well known that patients with aortic stenosis and especially regurgitation can remain asymptomatic in spite of severe haemodynamic impairment ${ }^{[1,15,33,37,38]}$. In asymptomatic and mildly symptomatic patients signs of haemodynamic severity of the disease such as the pressure gradient, valve orifice area and the regurgitant fraction as well as left ventricular function variables such as end-diastolic pressure, cardiac index and ejection fraction were usually less impaired than in severely symptomatic patients but predictive value of these variables in individual cases is minimal due to the large overlap between the two groups. For clinical decision-making, a combination of haemodynamic severity variables and symptomatic status was very helpful. In haemodynamically and symptomatically 
Table 4 Mean survtval in aortic stenosts after onset of angina, syncope and congestive heart failure

\begin{tabular}{|c|c|c|c|c|c|}
\hline \multirow[b]{2}{*}{ Author } & \multirow[b]{2}{*}{ Period of study } & \multirow{2}{*}{$\begin{array}{l}\text { No. of } \\
\text { patients }\end{array}$} & \multicolumn{3}{|c|}{ Mean survival (years) } \\
\hline & & & Angina & Syncope & $\begin{array}{l}\text { Congestive heart } \\
\text { fallure }\end{array}$ \\
\hline Contratto ${ }^{[12]}$ & $1913-1935$ & 180 & $3 \cdot 3$ & 0.8 & 0.5 \\
\hline Mitchel[ ${ }^{[1]]}$ & $1913-1952$ & 37 & $4 \cdot 0$ & 3.0 & 1.9 \\
\hline Olesen $^{[14]}$ & $1933-1949$ & 42 & $4 \cdot 7$ & $3 \cdot 2$ & 1.0 \\
\hline Bergeron ${ }^{[19]}$ & $1943-1952$ & 100 & $2 \cdot 0$ & $2 \cdot 0$ & $1 \cdot 0$ \\
\hline Takeda ${ }^{[1 t]}$ & $1948-1959$ & 60 & $4 \cdot 4$ & $3 \cdot 8$ & $2 \cdot 8$ \\
\hline Blondeau ${ }^{[17]}$ & $1949-1964$ & 88 & $4 \cdot 5$ & $3 \cdot 1$ & $1 \cdot 3$ \\
\hline Anderson ${ }^{[1 x]}$ & $<1961$ & 100 & - & - & $2 \cdot 2$ \\
\hline $\operatorname{Loogen}^{[2]]}$ & $1960-1970$ & 41 & $3 \cdot 5$ & - & - \\
\hline $\operatorname{Ross}^{[32]}$ & Review 1968 & - & $4 \cdot 0$ & 3.0 & $2 \cdot 0$ \\
\hline
\end{tabular}

Table 5 Actuarlal survival in aortic stenosts in relation to New York Heart Associatton classification

\begin{tabular}{|c|c|c|c|c|c|}
\hline \multirow{2}{*}{ Author } & \multirow{2}{*}{ Penod of study } & \multirow{2}{*}{$\begin{array}{c}\text { No. of } \\
\text { patients }\end{array}$} & \multirow{2}{*}{ NYHA class } & \multicolumn{2}{|c|}{ Actuarial survival } \\
\hline & & & & 2 year & 5 year \\
\hline 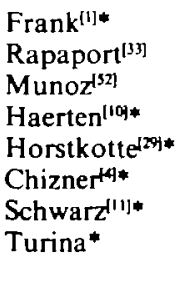 & $\begin{array}{r}1954-1972 \\
1955-1975 \\
1964-1974 \\
1967-1976 \\
1968-1981 \\
<1978 \\
1975-1982 \\
1963-1983\end{array}$ & $\begin{array}{r}15 \\
42 \\
43 \\
35 \\
35 \\
42 \\
28 \\
110\end{array}$ & $\begin{array}{c}\text { I-III } \\
\text { various } \\
\text { II-IV } \\
\text { III-IV } \\
\text { III-IV } \\
? \\
\text { III-IV } \\
\text { I-II } \\
\text { III-IV }\end{array}$ & $\begin{array}{l}85 \% \\
56 \% \\
98 \% \\
39 \% \\
46 \% \\
52 \% \\
76 \% \\
99 \% \\
31 \%\end{array}$ & $\begin{array}{c}52 \% \\
38 \% \\
64 \% \\
17 \% \\
18 \% \\
- \\
- \\
76 \% \\
22 \%\end{array}$ \\
\hline
\end{tabular}

NYHA $=$ New York Heart Association

*Studies in which heart catheterizations were performed

Table 6 Actuarial survival in aortic regurgitation in relatton to severity of the disease or symptomatic status

\begin{tabular}{|c|c|c|c|c|c|}
\hline \multirow{2}{*}{ Author } & \multirow{2}{*}{ Penod of study } & \multirow{2}{*}{$\begin{array}{c}\text { No. of } \\
\text { patients }\end{array}$} & \multirow{2}{*}{ Severity of disease } & \multicolumn{2}{|c|}{ Actuarial survival } \\
\hline & & & & 2 year & 5 year \\
\hline Bland ${ }^{(20)}$ & $1921-1943$ & 87 & 'High degree' & - & $76 \%$ \\
\hline Masse $^{\mid 21\}}$ & $<1966$ & 14 & $\mathrm{CHF}$ & $7 \%$ & - \\
\hline \multirow{2}{*}{ Hegglin $^{[3]}$} & review 1968 & - & $\mathrm{CHF}$ & $38 \%$ & $15 \%$ \\
\hline & & & Angina & $85 \%$ & $45 \%$ \\
\hline Loogen $^{(2)}$ & $1960-1970$ & 18 & $\mathrm{CHF}$ & \multicolumn{2}{|c|}{$11 \%$ (first year) } \\
\hline Rapapor ${ }^{[3]]}$ & $1955-1975$ & 35 & Various & $82 \%$ & $75 \%$ \\
\hline Haerten ${ }^{1194 *}$ & $1967-1976$ & 30 & NYHA III-IV & $54 \%$ & $37 \%$ \\
\hline Horstkotte ${ }^{[2]}$ & $1968-1981$ & 25 & NYHA III-IV & $51 \%$ & $38 \%$ \\
\hline Schwarz ${ }^{(1) *}$ & $1975-1985$ & 40 & NYHA II-IV & $92 \%$ & $66 \%$ \\
\hline \multirow[t]{2}{*}{ Turina* } & $1963-1983$ & 80 & NYHA I-II & $93 \%$ & $73 \%$ \\
\hline & & & NYHA III-IV & $57 \%$ & $29 \%$ \\
\hline
\end{tabular}

$\mathrm{CHF}=$ congestive heart failure, NYHA $=$ New York Heart Association class

*Studies in which heart catheterizations were performed 
severe aortic stenosis as well as in regurgitation, immediate aortic valve surgery should be performed. Any delay in surgical treatment can have deleterious impact on survival. High mortality in patients waiting for aortic valve surgery is a well known but seldom reported problem ${ }^{[27,28,38-40]}$. During the 1970-1982 period, mortality rate in patients waiting for aortic valve replacement was $3.9 \%$ with average heart catheterization-operation delay of $2 \cdot 6$ months whereas during the same period operative mortality was only $2.5 \%$. The majority of patients who died before operation had aortic stenosis but premature death also occurred in aortic regurgitation $^{[20,27,38]}$. Less clear is the situation in asymptomatic and mildly symptomatic patients with severe disease. In our cohort with aortic stenosis or combined lesions, none of the patients died or required operation within the first 2 years after heart catheterization. Even after 5 years, $75 \%$ of them were event-free. However, sudden and unexpected death in asymptomatic or mildly symptomatic patients with aortic stenosis has been reported ${ }^{[1,32,41]}$. In aortic stenosis, sudden death is responsible for about $20 \%$ of all death cases and occurs in the great majority of patients only during the late stage of the disease in severely symptomatic patients ${ }^{[13,16,17,32,41]}$. It has been estimated that only $3-5 \%$ of all sudden death cases occurred in asymptomatic patients ${ }^{[32]}$. Because such a small but definitive risk of sudden death in asymptomatic patients with severe aortic stenosis exists, aortic valve surgery is recommended even for asymptomatic children with severe stenosis $^{\mid 42\}}$. There is, however, an important difference of surgical treatment of aortic valve disease in children and adults. In children aortic commissurotomy, today an operation with minimal mortality and without postoperative procedure related morbidity, is usually performed. In adults, aortic valve replacement is required, an operation which has some small mortality risk even when performed by experienced surgeons and, more importantly, a persistent postoperative morbidity and mortality risk related to the prosthetic valve. In our experience the risk of delayed operation in asymptomatic and mildly symptomatic patients with severe aortic stenosis is minimal and does not justify immediate valve replacement. Recently an identical opinion was expressed based on the result of a follow-up study in patients re-evaluated non-invasively by Doppler technique ${ }^{[43]}$. In aortic stenosis, in contrast to aortic regurgitation, the risk of aortic valve replacement in patients with poor left ventricular function in the absence of coronary artery disease is not necessarily increased and an improvement of left ventricular function can be expected postoperatively in the majority ${ }^{[44.49}$.

In aortic regurgitation, the situation is even more complex. Only a minority of patients are severely symptomatic in the presence of haemodynamically severe disease. Severely symptomatic patients have a grim prognosis without operation and even after successful operation their long-term results may be poor ${ }^{[38.46-48]}$. That these patients should be operated upon as soon as possible is not questioned ${ }^{[48,49]}$. Within the first 2 years, we lost two asymptomatic patients with severe regurgitation from sudden and unexpected death, and even at 5 years event-free and effective survival was lower than in the corresponding aortic and stenosis group. During recent years, an intensive search for variables predictive of unsuccessful postoperative survival in aortic regurgitation has been initiated because the long-term results of operation were not entirely satisfactory when only severely symptomatic patients were referred to surgery ${ }^{[38,46,48]}$. None of the recommended non-invasive and invasive variables has been widely accepted. In our clinic, encouraged by low operative and late mortality and worried by the possibility of sudden death before operation, we today suggest valve replacement even in asymptomatic patients when marked dilatation of the left ventricle is present and the shortening variables are decreasing. As measures of left ventricular dilatation echocardiographic end-diastolic and endsystolic diameters over 75 and $55 \mathrm{~mm}$ respectively and an end-diastolic volume index over $200 \mathrm{ml} \mathrm{m}^{-2}$ are used. With this policy, we have lost no patient before operation during the last 10 years and the 5 year postoperative survival has exceeded $90 \%{ }^{[50]}$.

The rate of progression of aortic valve disease in asymptomatic and mildly symptomatic patients as well as in patients with moderate disease is scarcely predictable. Although, in our aortic stenosis group, patients with more advanced disease were coming to operation earlier than those with less advanced disease, a large over-lap between the two groups made any predictability in individual cases impossible. Within 2 to 3 years a previously moderate stenosis or regurgitation can become symptomatically and haemodynamically severe; on the other hand patients with severe disease can remain asymptomatic for 10 and more years. A similar experience has been reported by others ${ }^{[-9]}$. These observations underline the need for regular follow-up examinations of patients with severe or moderate aortic valve disease, not only by clinical means but also by 
modern noninvasive methods because worsening of left ventricular function is not always preceded by worsening of the symptomatic status. Patients should be urged to report new symptoms such as presyncopal attacks and dizziness or a decrease of working or sport capacity. In mild aortic valve disease within the first 5 years after diagnosis no close surveillance is required for patients in a stable condition. A rapid progression of aortic stenosis has been occasionally reported but was always preceded by symptomatic deterioration ${ }^{[6.53]}$.

The presence of additional coronary artery disease influences the outcome of patients considerably, regardless of the severity of aortic valve disease. Angina pectoris is an unreliable indicator of the presence of coronary artery disease because only a minority of angina patients had coronary lesions and on the other hand some $20 \%$ to $25 \%$ of coronary artery disease patients are free of angina $^{[5 i]}$. This observation underlines the importance of coronary arteriography in aortic valve disease. Patients in whom additional coronary artery disease is suspected on clinical grounds, patients above the age of 40 as well as patients with marked risk factors should undergo coronary arteriography.

Patients with aortic valve disease have a risk of infective endocarditis which amounts to $0.5 \%$ per patient-year. Although in the acute phase of the disease the risk of mortality was small, the outlook of these patients is compromised due to rapid deterioration of valve function even after successful antibiotic treatment. Close surveillance and reevaluation of valve function after infective endocarditis is required, regardless of actual symptoms.

Summing-up our experience, it is evident that haemodynamically and symptomatically severe aortic stenosis and regurgitation have a very poor prognosis and require immediate valve surgery. Asymptomatic and mildly symptomatic patients with severe aortic stenosis are at low risk and surgical treatment can be postponed until marked symptoms appear without a significant risk of death. In severe aortic regurgitation, the need for surgery is not dependent only on symptoms but should be considered even in asymptomatic or mildly symptomatic patients with massively enlarged hearts because of the risk of sudden and unexpected death. In the absence of coronary artery disease, moderate aortic valve disease does not require operation for prognostic reasons. The rate of progression of severe and moderate aortic valve disease is scarcely predictable and these patients require continuous and close surveillance. In mild aortic valve disease within the first 5 years after diagnosis, frequent follow-up examinations of patients in stable clinical condition are not needed.

\section{References}

[1] Frank S, Johnson A, Ross J. Natural history of valvular aortic stenosis. Br Heart J 1973; 35: 41-6.

[2] Goldschlager N, Pfeifer J, Cohn K, Popper R, Selzer A. The natural history of aortic regurgitation. Am J Med 1973; 54: 577-88.

[3] Wagner HR, Ellison RC, Keane JF, Humphries JO, Nadas AS. Clinical course in aortic stenosis. Circulation 1977; 56 (Supp 1): I-47-56.

[4] Chimer MA, Pearle DL, DeLeon AC. Natural history of aortic stenosis in adults. Chest 1978; 74: 333 (Abstr).

[5] Bogart DB, Murphy BL, Wong BYS, Pugh DM, Dunn MI. Progression of gortuc stenosis. Chest 1979; 76 : 391-6.

[6] Chestlin MD, Gertz EW, Brundage BH, Carlson CJ, Quash JA, Bode RS. Rate of progression of severity of valvular aortic stenosis in the adult. Am Heart J 1979; 98: 689-700.

[7] Wagner S, Selzer A. Patterns of progression of aortic stenosis: a longitudinal hemodynamic study. Circulation 1982; 65: 709-12.

[8] Nestico PF, DePace NL, Kimbiris D et al. Progression of isolated aortic stenosis: analysis of 29 patients having more than one cardiac catheterization. Am J Cardiol $1983 ; 52: 1054-8$

[9] Jonasson R, Jonsson B, Nordlander R, Orinius E, Szamosi A. Rate of progression of severity of valvular aortic stenosis. Acta Med Scand 1983; 21 3: 51-4.

[10] Haerten K, Dohn G, Dohn V, Seipel L, Loogen F. Natuerlicher Verlauf operationswuerdiger Aortenklappenvitien bei konservativer Therapie. Z Kardiol 1980; 69: 757-62.

[11] Schwarz F, Ehrmann J, Olschewski M et al. Langzeitprognose medikamentoes und chirurgisch behandelter Patienten mit erworbenen Aortenklappenfehlern: ueberlebensstatistik und multivariate Cox-Regressionsanalyse. Z Kardiol 1985; 74: 598-603.

[12] Contratto AW, Levine SA. Aortic stenosis with special reference to angina pectoris and syncope. Ann Int Med 1936; 10: 1637-53.

[13] Mitchell AM, Sackett CH, Hunzicker WJ, Levine SA. The clinical features of aortic stenosis. Am Heart J 1954; 48: 684-720.

[14] Olesen KH, Warburg E. Isolated aortic stenosis - the late prognosis. Acta Med Scand 1958; 160: 437-46.

[15] Bergeron J, A belmann WH, Vazquez-Milan H, Ellis LB Aortic stenosis - clinical manifestations and course of the disease. Arch Int Med 1954; 94: 911-23.

[16] Takeda J, Warren R, Holzman D. Prognosis of aortic stenosis. Arch Surg 1963; 87: 931-6.

[17] Blondeau M, Maurice P, Lenegre J. Histoire naturelle du retrecissement aortique calcifie non opere. Arch Mal Coer 1969; 62: 1685-99.

[18] Anderson MW. The clinical course of patients with calcific aortic stenosis. Proc Staff Meet Mayo Clin 1961; 36: $439-44$. 
[19] Segal J, Harvey WP, Hufnagel CA. Clinical study of one hundred cases of severe aortic insufficiency. Am J Med 1956;21: 200-10.

[20] Bland EF, Wheeler EO. Severe aortic regurgitation in young people. A long term perspective with reference to prognosis and prosthesis. N Engl J Med 1957; 256: $667-71$.

[21] Massell BF, Amezcua FJ, Czoniczer G. Prognosis of patients with pure or predominant aortic regurgitation in the absence of surgery. Circulation 1966: 34 (Suppl III): III-164 (Abstr).

[22] Spagnuolo M, Kloth H, Taranta A, Doyle E, Pasternack B. Natural history of rheumatic aortic regurgitation. Criteria predictive of death, congestive heart failure and angina in young patients. Circulation $1971 ; 44$ : 368-80.

[23] Smith HJ, Neutze JM, Roche AHG, Agnew TM, Barratt-Boyes BG. The natural history of rheumatic aortic regurgitation and the indications for surgery. $\mathrm{Br}$ Heart J 1976; 38: 147-54.

[24] Gorlin R, Gorlin SG. Hydraulic formula for calculations of the area of stenotic mitral valve, other cardiac valves and central circulatory shunts. Am Heart J 1951; 41: $1-10$.

[25] Cutler SJ, Ederer F. Maximum utilization of Lfe table method in analyzing survival. J Chronic Dis 1958; 8: 699-712.

[26] Peto R, Pike MC. Conservatism of the approximation $(\mathrm{O}-\mathrm{E})^{2} / \mathrm{E}$ in the logrank test for survival data or tumor incidence data. Biometrics 1973; 29: 579-84.

[27] Loogen F. Indikation zum Herzklappenersatz. Verhandl Dtsch Ges Kreislauff 1970; 36: 1-10.

[28] Matthews AW, Barritt DW, Keen GE, Belsey RH. Preoperative mortality in aortic stenosis. Br Heart J 1974; 36: 101-3.

[29] Horstkotte D, Loogen F, Kleikamp G, Schulte HD, Trampisch HJ, Bircks W. Der Einfluss des prosthetischen Herzklappenersatzes auf den natuerlichen Verlauf von isolierten Mitral- und Aortenklappenfehlern sowte Mehrklappenerkrankungen. Klinische Ergebnisse bei 783 Patienten bis zu 8 Jahren nach Implantation von Björk-Shiley-Kippscheibenprothesen. Z Kardiol 1983; 72: 494-503.

[30] Cohen LS, Friedman WF, Braunwald E. Natural history of mild congenital aortic stenosis elucidated by serial hemodynamical studies. Am J Cardiol 1972; 30: $1-5$.

[31] Bonow RO, Rosing DR, McIntosh CLet al. The natural history of asymptomatic patients with aortic regurgitation and normal left ventricular function. Circulation 1983; 68: 509-17.

[32] Ross J, Braunwald E. Aortic stenosis. Circulation 1968; $27 \& 28$ (Supp V): V-61-7.

[33] Rapaport E. Natural history of aortic and mitral valve disease. Am J Cardiol 1975; 35: 221-7.

[34] Bloemer H, Delius W, Sebening H. Natuerlicher Verlauf bei Patienten mit Mitral- und Aortenklappenfehlern. Z Kardiol 1977; 66: 159-69.

[35] Dry TJ, Willius FA. Calcareous disease of the aortic valve. Am Heart J 1939; 17: 138-57.
[36] Braunwald E, Goldblatt A, Aygen MM, Rockoff SD, Morrow AG. Congenital aortic stenosis. Circulation 1963; 27: 426-62.

[37] Hegglin R, Scheu H, Rothlin M. Aortic insufficiency. Circulation 1968; 37 \& 38 (Supp V): V-77-92

[38] Turnna J, Tunna M, Rothlin M, Krayenbuehl HP. Improved late survival in patients with chronic aortic regurgitation by earlier operation. Circulation 1984; 70 (Supp I): I-147-52.

[39] Harken DE, Black H, Taylor WJ, Thrower WB, Soroff HS. The surgical correction of calcific aortic stenosis in adults. J Thorac Surg 1958; 36: 759-73.

[40] Brandenburg RO. Medical problems of aortic valve replacement. Prog Cardiovasc Dis 1965; 7: 531-43.

[41] Glew RH, Varghese PJ, Krovetz LJ, Dorst JP, Rowe RD. Sudden death in congenital aortic stenosis. Am Heart J 1969; 78: 615-25.

[42] Nadas AS. Clinical course of aortic stenosis. Summary and conclusions. Circulation 1977; 56 (Supp I): I-70-1.

[43] Kelly TA, Smucker Ml, Rothbart RM, Gibson RS. Do asymptomatic patients with aortic stenosis require valve replacement surgery? J Am Coll Cardiol 1986; 7: 101 (Abstr).

[44] Smith N, McAnulty JH, Rahimtoola SH. Severe aortic stenosis with impaired left ventricular function and clinical heart failure: Results of valve replacement. Circulation 1978; 58: 255-64.

[45] Thompson R, Yacoub M, Ahmed M, Seabra-Gomes R, Rickards A, Towers M. Influence of preoperative left ventricular function on results of homograft replacement of the aortic valve for aortic stenosis. Am J. Cardiol 1979; 43: 929-38.

[46] Bonow RO, Rosing DR, Kent KM, Epstein SE. Timing of operation for chronic aortic regurgitation. Am J Cardiol 1982; 50: 325-36.

[47] Thompson R. Aortic regurgitation. How do we judge optimal timing for surgery. Aust NZ J Med 1984; 14: 514-20.

[48] Rahimtoola SH. Valvular heart disease: the decision to treat. Hosp Pract 1984; 19: 63-78.

[49] O'Rourke RA, Crawford MH. Timing of valve replacement in patients with chronic aortic regurgitation. Circulation 1980; 61: 493-5.

[50] Turina J, Hess O, Turina M, Krayenbuehl HP. Is postoperative survival in aortic valve disease dependent upon preoperative LV function. Eur Heart J 1985; 6 (Suppl 1): 32 (Abstr)

[51] Turina J, Goebel N, Hess O, Krayenbuehl HP. Indications for coronary arteriography in aortic valve discase. Z Kardiol 1986; 75 (Suppl 2): 68-72.

[52] Munoz S, Gallardo J, Diaz Gorrin JR, Medina $O$. Influence of surgery on the natural history of rheumatic mitral and aortic valve disease. Am J Cardiol 1975; 35: $234-42$.

[53] Brooks N. Rapid development of severe aortic stenosis from calcification of congenital bicuspid valve. Br Med J 1980; 281: 424-5. 